\title{
Vaginoplasty: A case series comparing three different operative techniques
}

\author{
Akanksha G. Allahbadia ${ }^{1}$, Chandrakant S. Madkar ${ }^{2, *}$, Hemant G. Deshpande ${ }^{3}$, Nilesh Unmesh Balkawade \\ ${ }^{\mathbf{1}}$ Resident IIIrd year, ${ }^{2}$ Professor, ${ }^{3}$ Professor \& HOD, ${ }^{4}$ Lecturer, Dept. of Obstetrics and Gynecology, Dr. D. Y. Patil Medical \\ College and Research Centre, Pimpri, Pune, Maharashtra, India
}

*Corresponding Author:

Email: drcsmadkar@gmail.com

\begin{abstract}
Introduction: Vaginal agenesis may present as a single defect in development or associated with other anomalies. It is usually associated with Mayer-Rokitansky-Kuster-Hauser (MRKH) and Androgen Insensitivity Syndromes (AIS). The incidence is about 1 in 4000-5000 live female births. This is a case series of six cases of vaginoplasties performed by three varied surgical techniques over a period of two years, with a follow up.

Cases: A comparison of three techniques of vaginoplasties was done. Six total cases were included-three cases using modified McIndoe's technique with amnion graft, two using split thickness skin graft and one by Laparoscopic Peritoneal Pull through technique.

Patients were followed up meticulously over the course of two years and results were recorded. The comparison scoring was done based on relative ease of the operative procedure, pain experienced, vaginal depth on follow up, uptake of graft and sexual satisfaction in the married females.

Result: Despite new techniques of vaginoplasty advancing over the years such as laparoscopic approaches and use of different materials as grafts, vaginoplasty with amnion graft is stillpreferredfor the treatment of vaginal agenesis. The technique is simple and safe and provides a satisfactory and functional vagina in majority of the patients.
\end{abstract}

Keywords: Vaginoplasty, Mayer-Rokitansky-Kuster-Hauser, McIndoe's technique, Neo-vagina.

\section{Introduction}

Mayer-Rokitansky-Kuster-Hauser (MRKH) is the most common syndrome associated with vaginal agenesis. Primary amenorrhea the most common clinical presentation in unmarried, pubertal age females and dyspareunia or primary infertility in newly married women. Women commonly present with normal secondary sexual characters, normal ovarian function and normal intelligence. ${ }^{2,3}$ They are eugonadotropic and have a female phenotype with 46 XX Karyotype. ${ }^{3}$ The only exception is Androgen Insensitivity Syndrome where the Karyotype is $46 \mathrm{XY}$.

On examination they are found to have a vaginal dimple or shallow pouch upto $2 \mathrm{~cm}$ in length. Congenital absence of uterus, cervix and vagina is normally seen. ${ }^{1}$

Total absence of Mullerian development will lead to aplasia, while the partial development which is a common occurrence leads to tubal and partial uterine development and complete absence of upper three fourth of vagina. ${ }^{1}$

The main aim of treatment in MRKH syndrome patients is to solve problems of sexual life by reconstruction of the vagina. ${ }^{4}$ Thebest timing for the creation of a neo-vagina is when the patient is emotionally mature, highly motivated and mentally ready for correction. ${ }^{5}$

Nonsurgical methods have been advocated by the American College of Obstetricians and Gynecologists (ACOG) as the first line of treatment. ${ }^{6}$

A case series has more than four patients while four patients or less should be reported. ${ }^{7}$ We studied six cases of women in the reproductive age group with MRKH syndrome. Three surgical methods compared in this study include modification of McIndoe's vaginoplasty using Amnion graft which was used for three cases, two cases using split thickness skin graft and one using laparoscopic peritoneal pull technique (Modified Davydov's technique).

The aim of this study was to compare the outcomes of three different surgeries for creation of a neo vagina. Operative time, blood loss and post-operative pain score was compared. Coital function post surgery was compared in sexually active patients.

\section{Materials and Methods}

This is a series of cases carried out in a tertiary care institute over a period of two years from May 2015 to September 2017.All six patients were in the age group of 18-25 years. Two were married and four were unmarried. Three married after surgery.

Three graft materials used were fresh triple-washed amnion harvested from placenta, split thickness skin graft harvested from the thigh and peritoneum. Surgeries were performed after taking valid written informed consents from all the patients.

Six patients were followed up meticulously over the course of three years and results were recorded. The comparison scoring was done based on relative ease of the operative procedure, blood loss, vaginal depth on follow up, pain scoring ${ }^{8}$ and sexual satisfaction in the married females. 

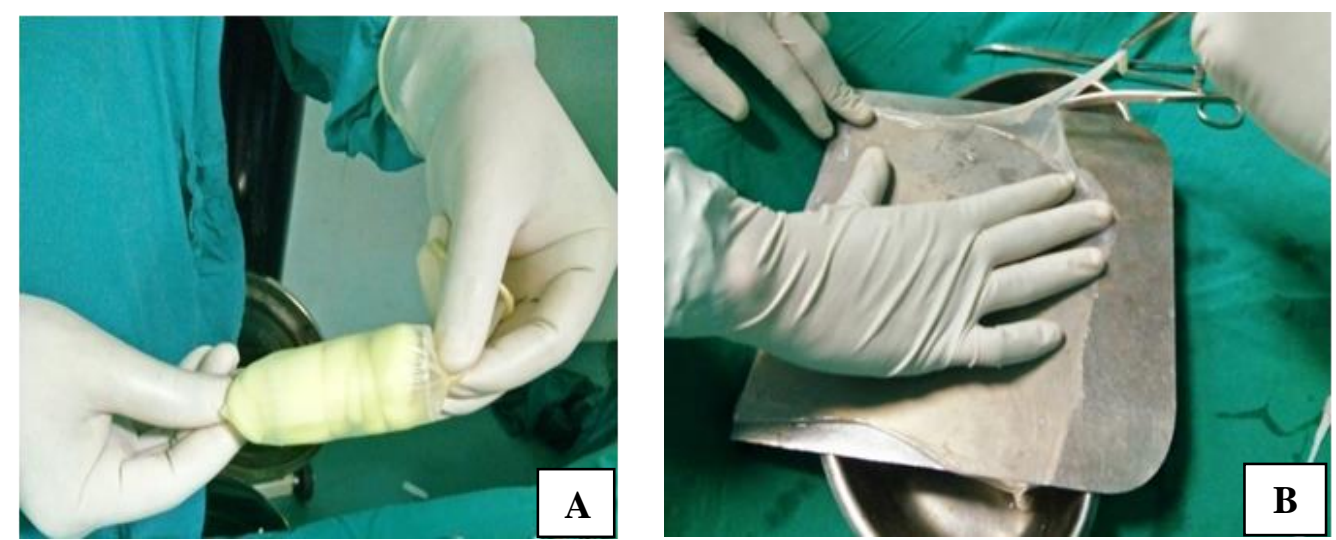

Fig. 1: a) Mould lined by amnion graft b) Graft preparation

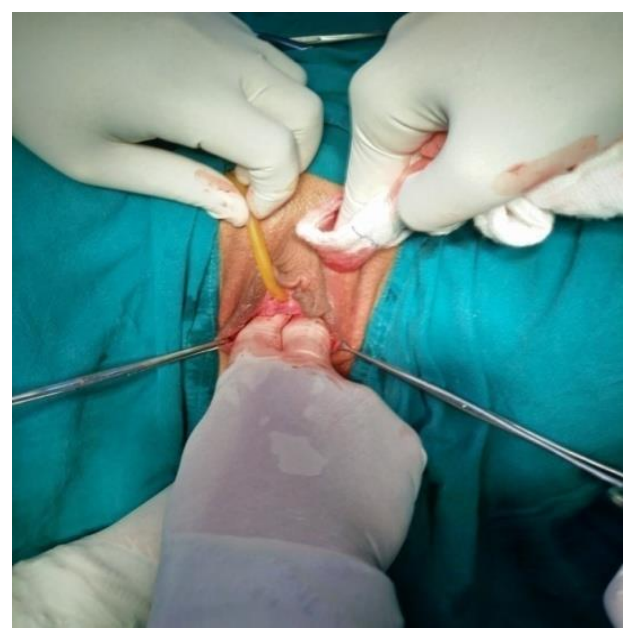

Fig. 2: Neo-Vagina Creation

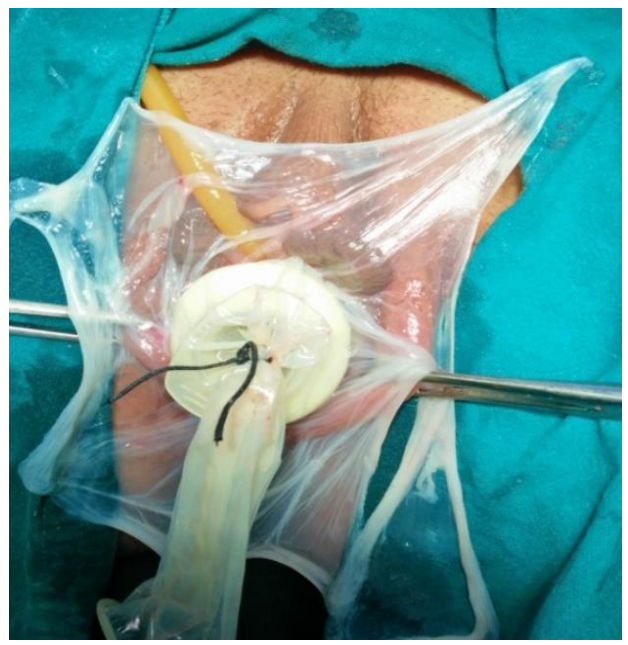

Fig. 3: Amnion graftfor lining the neo-vagina McIndoe's method

The first technique using an artificial mould coated with a fresh amnion graft. Three cases were done using amnion graft. One case scenario is described here. A 19 year old unmarried MRKH patient presented with primary amenorrhea.

Amnion graft was harvested from a placenta of a Caesarean section patient and triple washed with antibiotics and normal saline. Patient was status negative and free of any high risk factor. As opposed to a gauze based mould as described in literature, use of an acrylic mould again fabricated over a $10 \mathrm{ml}$ syringe maintains neo-vaginal cavity Indian Journal of Obstetrics and Gynecology Research, January-March, 2018;5(1):148-153 
volume and prevents graft contracture. ${ }^{9}$ The soft vaginal mould was created using a $10 \mathrm{ml}$ syringe, a layer of soft sponge and covered with a condom. The amnion graft was sutured over the mould.

Transverse incision was made in the vaginal dimple to create a pocket between urinary bladder and rectum. After vaginal dilatation with serial dilators, amniotic membrane graft was taken and placed on the upper and lower vaginal wall. The vaginal mould wasintroduced and the amnion graft over it was sewn to external mucosa. On the $7^{\text {th }}$ postoperative day, the mould was removed. The time of surgery was 45 minutes and blood loss was less than 30 $\mathrm{ml}$.

At 7 days, the graft was well taken up and there was no pressure necrosis or ulceration.A new mould was prepared, using a syringe coated with foam covered with condom and was advised to place it in the vagina for 24 hours for six weeks and only at night in the next six weeks, except at the time of defecation and micturition. The neo-vaginal length was $10 \mathrm{~cm}$. Pain scoring was done using the Visual Analogue Scale (VAS) from 1-10, with 10 being the maximum. At time of surgery by this method it was 5, during post operative dilation it was 6 and at 3 month follow up was 2.The uptake of graft was good. No complications were reported.

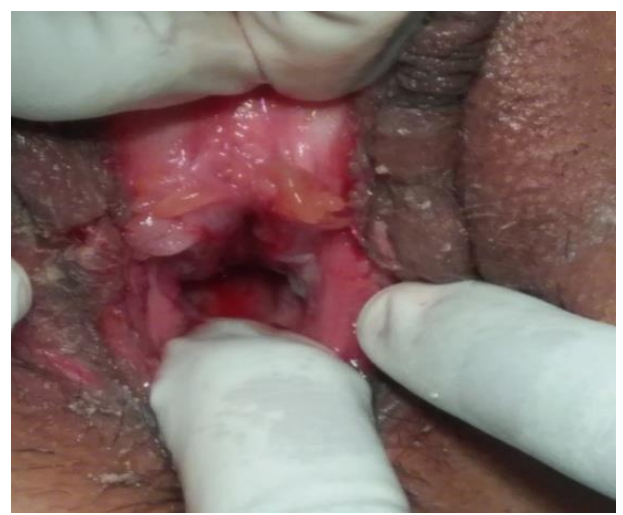

Fig. 4: Uptake of Amnion Graft after 7 days

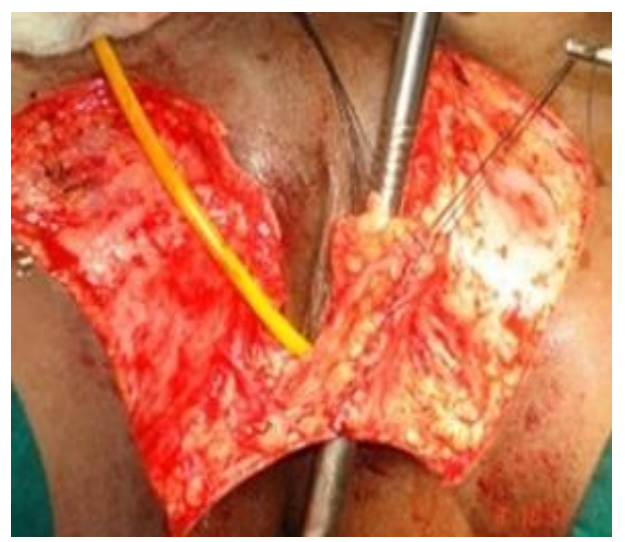

\section{Fig. 5: Split Thickness Skin Graft}

The second technique employed was vaginoplasty by McIndoe's method using split thickness skin graft. Two cases were done using this method of which one is described below. A 20 year old unmarried woman presented with primary amenorrhea. Patient was getting married in 6 months time. A plastic surgeon was called in to harvest the skin graft and he used a Padgett's dermatome for the same.

An artificial mould was created using dental impression material and a split thickness skin graft from the patient's thigh was harvested. McIndoe's Procedure was followed for creation of a neo-vagina. Graft was harvested from bilateral thighs and was less than $0.5 \mathrm{~cm}$ thick, $17-18 \mathrm{~cm}$ wide and long. A mould was shaped using $3 \mathrm{M}$ Putty Material and covered with a layer of soft sponge and a condom.The graft was sewn onto this mould using Mattress sutures with Vicryl 4-0 and introduced into the neo-vagina. Mould coated with graft was kept in situ for 8 days. Time of surgery was 90 minutes, blood loss was less than $50 \mathrm{ml}$. The vaginal length was $12 \mathrm{~cm}$. Pain score at time of surgery was 4 , during post operative dilation was 8 and at 3 month follow up was 4 . Dressing was done daily over the site of the donor graft.

After 8 days, careful inspection of mould and uptake of graft was visualized, which was satisfactory. Patient was taught management of the mould and asked to follow up after 6 weeks. Patient counseled that dry dyspareunia 
may occur when intercourse commences and rarely hair growth may be seen in the graft. Lubrication advised and patient followed up regularly.

The third technique used was peritoneal pull through vaginoplasty with Laparoscopic assistance by Modified Davydov's method in a 19 year old married patient presenting with primary infertility and dyspareunia.Transverse vaginal septum along with absence of upper $3 / 4^{\text {th }}$ of vagina was seen.

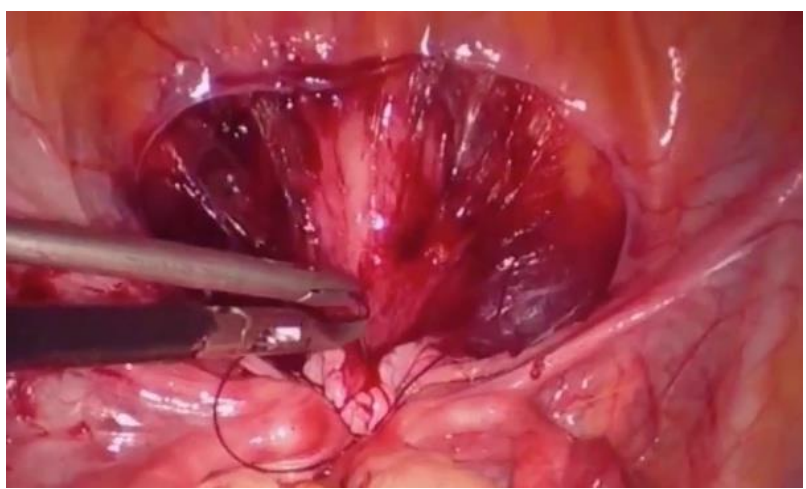

\section{Fig. 6: Laparosopic Modification of Davydov's technique}

Laparoscopic incisions of the pelvic peritoneum were made anteriorly and laterally to mobilize it. From below after excising septum, creation of a neo-vagina was done using McIndoe's technique. Vaginal vault was visualized from above, incised and peritoneum was brought down and sutured to external mucosa. Using purse string sutures to posterior and lateral walls of pelvis, apex of neo vagina created. Blood supply from source was maintained and no need for a mould.Patient was advised abstinence for 6 weeks and regular sexual intercourse after that period.

Time of surgery was 120 minutes and blood loss was less than $100 \mathrm{ml}$. Patient was followed up at 10 days, 6 weeks and 3 months. Vaginal length was $13 \mathrm{~cm}$, Pain score at time of surgery was 2, during post operative phase was 3 and at 3 month follow up was 2. Uptake of peritoneal lining was good and patient had no dyspareunia after 6 weeks.

\section{Results}

All 6 patients developed functional neo-vaginas. Graft uptake was good in all cases. Differences were seen in ease of operative procedure, post operative pain scoring and duration of hospital stay.

Table 1

\begin{tabular}{|c|c|c|c|c|c|c|c|c|c|c|}
\hline 它 & & 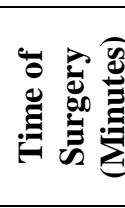 & 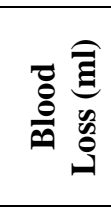 & 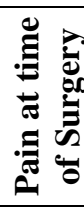 & 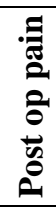 & 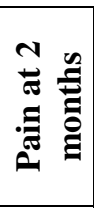 & 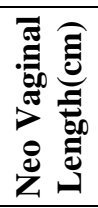 & 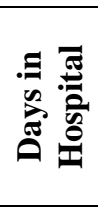 & 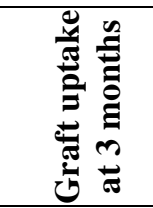 & 竭 \\
\hline 1 & Amnion Graft & 45 & $30 \mathrm{ml}$ & 5 & 6 & 3 & 10 & 10 & Good & None \\
\hline 2 & $\begin{array}{l}\text { Split Thickness } \\
\text { Skin Graft }\end{array}$ & 90 & $50 \mathrm{ml}$ & 4 & 8 & 4 & 10 & 14 & Good & $\begin{array}{c}\text { Dry } \\
\text { Dyspareunia }\end{array}$ \\
\hline 3 & Amnion Graft & 50 & $40 \mathrm{ml}$ & 6 & 7 & 3 & 9 & 9 & Good & None \\
\hline 4 & $\begin{array}{l}\text { Split Thickness } \\
\text { Skin Graft }\end{array}$ & 80 & $45 \mathrm{ml}$ & 4 & 7 & 4 & 11 & 20 & Good & None \\
\hline 5 & Amnion Graft & 45 & $50 \mathrm{ml}$ & 5 & 6 & 3 & 9 & 9 & Good & None \\
\hline 6 & $\begin{array}{l}\text { Laparoscopic } \\
\text { Peritoneal } \\
\text { Pull Through }\end{array}$ & 120 & $100 \mathrm{ml}$ & 2 & 3 & 2 & 13 & 4 & Excellent & None \\
\hline
\end{tabular}

\section{Discussion}

MRKH syndrome is the second most common cause of primary amenorrhea. ${ }^{2}$ The incidence is about 1 in 4000-5000 live female births. ${ }^{1,2}$

The typical form is seen in $47 \%$ of patients, the atypical form in $21 \%$ and $32 \%$ present with the most marked form-the MURCS association which is an acronym for (MU)llerian, (R)enal, (C)ervicothoracic (S)omite abnormalities and is a developmental disorder that primarily affects the uro-genital system. ${ }^{(10)}$

MRKH syndrome is associated with the Wnt family member 4 (Wnt4) mutation, LIM homeobox 1 (LHXI), HNF1 homeobox B $(H N F 1 B)$ and T-box 6 $\left(\right.$ TBX6). ${ }^{3}$ 
A rareclinical association of MRKH syndrome is with rectovestibularfistula presenting in a female neonate with two openings in the introitus. Immediate surgical correction is required. ${ }^{11}$ Transvaginal ultrasound and Magnetic Resonance Imaging have been the best diagnostic options in MRKH syndrome. ${ }^{12}$

Women with Mayer-Rokitansky-Küster-Hauser (MRKH) syndrome may reproduce after In-Vitro Fertilization (IVF) using a gestational surrogate. Rare cases of MRKH patients reproducingafter uterine transplantation are being reported. ${ }^{13}$

For non-surgical management, Frank's graduated hard glass dilators followed by Ingram's (1981) dilators fixed to a bicycle seat mounted upon a stool were advised. Vaginal dilation can have a negative emotional impact on women and adequate counseling along with a psychological consult may be requiredprior to maximise efficacy. ${ }^{6,14}$

The Abbe-Wharton-McIndoe technique for creating a neo-vagina began in the year 1938 with attempts to create a space between the rectum and bladder. Balsa mould was used initially without a graft but this resulted in scarring and persistent granulation tissue. Sir Archibald McIndoe in England popularized the technique and used split-thickness skin graft along with continuous and prolonged post-operative dilation. ${ }^{15}$

The skin is harvested from a hair- free region of the body -either from the inguinal region, buttocks or inner thighs. The skin is harvested using an air powered or electrical dermatome. The harvested skin is folded over a foam mold and inserted in the newly dissected rectovesical space. Closure of the donor site is done with a vicryl 2-0 suture inserted subcutaneously to ensure hemostasis and cosmesis. The vaginal mold prevents restenosis of the neovagina and is kept in for a period of at least 10 days. $^{16}$

Tanncer and associates modified this procedure and used amnion graft first. Karjaleinen and associates advocated that amnion graft provided a better result than skin graft. ${ }^{15}$

Modifications of the McIndoe procedure consist of the use of human amnion, sigmoid colon, ileum, caecum, pudendal thigh flaps, fasciocutaneous flaps, gracilismyocutaneous flaps, labia minora flaps, flaps raised following tissue expansion of the labial pocket, peritoneum and bladder mucosa, the interceed absorbable adhesion barrier, autologous buccal mucosa and in recent times artificial dermis and recombinant basic fibroblast growth factor as neo-vaginal linings. ${ }^{17}$

William's vulvovaginoplasty, the Vecchietti traction procedure and Davydov's method are other commonly used methods for neo-vagina creation. ${ }^{14}$ The Vechietti procedure is now done Laparoscopically and has a high success rate. ${ }^{15}$

In the year 1969, Davydovinvented a three staged operation which requires dissection of the rectovesical space with abdominal mobilization of a segment of the peritoneum, and subsequently bringing down the peritoneum to attach at the introitus. ${ }^{6}$

Laparoscopic modification of Davydov's technique, first described by Templeman et al is a very safe and effective technique of vaginoplasty. ${ }^{15} \mathrm{~A}$ peritoneal $U$ shaped incision is taken to create a flap and a laparoscopic rectovesical access; besides, a rectal probe is used to identify a correct dissection plane. The peritoneum is stitched with the neo-vaginal edge and the upper vagina is made with a suture of the superior portion of serous membrane of the large intestine..$^{18}$

Bastu et al. carried out a study in which no dyspareunia was seen in patients who had a neo-vaginal length of $8 \mathrm{~cm}$ or more postoperatively by any procedure. For a successful surgery besides depth of the neo-vagina, a functional and sensitive vagina is important. $^{19}$

Post surgical complications include infections, vaginal stenosis, dry dyspareunia, prolapse and fistula. A dreaded post-surgical complication is utero-vesical fistula presenting as Youssef's Syndrome; a triad of menouria, amenorrhea and urinary continence. Its incidence has risen of late due to an increase in awareness in individuals about menstrual problems, good imaging modalities, early diagnosis of Mullerian anomalies and the advances in performing genital tract corrective surgeries. ${ }^{20}$ Fortunately in our case series there was no complication seen.

Vaginoplasty using an amnion graft is still a safe and effective procedure to treat patients of vaginal agenesis with shorter operating time of around 45 minutes, 30-50 ml blood loss on an average. However post operative pain was more based on the VAS scale ${ }^{8}$ and chances of stenosis were increased in a noncompliant patient.

Split Thickness skin graft provided longer vaginal length and decreased pain on the VAS scale, moderate blood loss. Chances of graft uptake were better than the amnion graft. However disadvantages include scar on the thigh with need for dressing, dry dyspareunia and chance of hair growth in the graft and need for a mould post-operatively.

Laparoscopic Peritoneal Pull Through method required the most surgical expertise, the longest operating time of 120 minutes and more chances of intra-operative complications.However the post operative recovery and graft uptake were most successful in this method.With no need for the mould, pain score was least in these patients.

\section{Conclusion}

Nonsurgical methods are still the first line of choice however patient compliance is the biggest problem. Since vaginal agenesis is a rare presentation, a large sample size study of comparison between three methods is required to give a statistically significant result and conclusion. 
Laparoscopic modification of Davydov's method provides the greatest patient comfort. Modifications of McIndoe's procedure using Split thickness skin graft and amnion graft are still excellent techniques to be used in smaller centres or in patients not suited to a major surgery.

Amnion graft being the easiest to obtain is still preferred in the Indian scenario for lower socioeconomic class patients however laparoscopy is the method of the future.

\section{Conflict of Interest: None Source of Support: None}

\section{References}

1. Mhatre P, Mhatre J, Sahu R. New laparoscopic peritoneal pull-through vaginoplasty technique, J Hum Reprod Sci. 2014 Jul-Sep;7(3):181-6.

2. Dasgupta S, Mukhopadhyay P, Sharma PP, Begum N, Kalra A. Mayer-Rokitansky-Kuster-Hauser Type-B Anomaly with MURCS Association and Gonadal Dysgenesis. Journal of Obstetrics and Gynaecology of India. 2012;62(Suppl 1):83-4. doi:10.1007/s13224-0130384-4.

3. Watanabe K, Kobayashi Y, Banno K, et al. Recent advances in the molecular mechanisms of MayerRokitansky-Küster-Hauser syndrome. Biomedical Reports. 2017;7(2):123-7. doi:10.3892/br.2017.929.

4. Liao L, Doyle J, Crouch NS, Creighton SM. Dilation as treatment for vaginal agenesis and hypoplasia: a pilot exploration of benefits and barriers as perceived by patients. J Obstet Gynaecol. 2006 Feb;26(2):144-8.

5. Gari A. MclndoeNeovagina in patients with Mullerian Agenesis: A single center experience. Pakistan Journal of Medical Sciences. 2017;33(1):236-240.

doi:10.12669/pjms.331.11867.

6. Committee opinion: no. 562: müllerian agenesis: diagnosis, management, and treatment. Obstet Gynecol. 2013 May;121(5):1134-7. doi: 10.1097/01.AOG.0000429659.93470.ed.

7. Abu-Zidan F, Abbas A, Hefny A. Clinical "case series": a concept analysis. African Health Sciences. 2012;12(4):557-62.

8. Campbell, W.I., Lewis, S. Visual analogue measurement of pain. Ulster Med. J1990;59:149-54

9. Mishra B, Janavar G, Pradeep Y, Singh AK, Kumar V, Upadhyay DN. Indigenous technique of fabricating vaginal mould for vaginal reconstruction and uterine drainage in McIndoevaginoplasty using $10 \mathrm{ml}$ syringe. Indian Journal of Plastic Surgery : Official Publication of the Association of Plastic Surgeons of India. 2016;49(1):76-80. doi:10.4103/0970-0358.182230.

10. Oppelt P, Renner SP, Kellermann A, Brucker S, Hauser GA, Ludwig KS, Strissel PL, Strick R, Wallwiener D, Beckmann MW.Clinical aspects of Mayer-RokitanskyKuester-Hauser syndrome: recommendations for clinical diagnosis and staging. HumReprod. 2006 Mar;21(3):7927. Epub 2005 Nov 10.

11. Tiwari C, Shah H, Waghmare M, Khedkar K. MayerRokitansky-Kuster-Hauser syndrome associated with rectovestibular fistula. Turkish Journal of Obstetrics and Gynecology. 2017;14(1):70-3. doi:10.4274/tjod.94809.

12. Bombard DS 2nd, Mousa SA. Mayer-Rokitansky-KusterHauser syndrome: complications, diagnosis and possible treatment options: A review. Gynecol Endocrinol. 2014
Sep;30(9):618-23. doi:10.3109/09513590.2014.927855. Epub 2014 Jun 20. Review.

13. Friedler S, Grin L, Liberti G, Saar-Ryss B, Rabinson Y, Meltzer S. The reproductive potential of patients with Mayer-Rokitansky-Küster-Hauser syndrome using gestational surrogacy: a systematic review; Reprod Biomed Online. 2016 Jan;32(1):54-61. doi: 10.1016/j.rbmo.2015.09.006. Epub 2015 Sep 25. Review.

14. Le A, Wang Z, Shan L, Xiao T, Zhuo R, Luo G. Peritoneal vaginoplasty by Luohu I and Luohu II technique: a comparative study of the outcomes.European Journal of Medical Research. 2015;20(1):69. doi:10.1186/s40001-015-0165-x.

15. TeLinde's textbook of Operative Gynecology. $11^{\text {th }}$ edition; Surgery for anomalies of Muellerian Ducts; Pg505-54.

16. Kayondo M, Njagi J, Mukasa PK, Margolis T. A modified neo-vagina procedure in a low resource urogynecological unit: a case report of a 21 year old with Mayer-Rokitansky-Küster-Hauser (mrkh) Syndrome operated at Mbarara referral hospital, Southwestern Uganda. BMC Urology. 2017;17:69. doi:10.1186/s12894017-0258-7.

17. Rathod S, Samal SK. Secondary Vaginal Atresia Treated with Vaginoplasty Using Amnion Graft: A Case Report. Journal of Clinical and Diagnostic Research : JCDR. 2014;8(11):OD05-OD06. doi:10.7860/JCDR/2014/10674.5207.

18. Pizzo A, Laganà AS, Sturlese E, et al. Mayer-RokitanskyKuster-Hauser Syndrome: Embryology, Genetics and Clinical and Surgical Treatment. ISRN Obstetrics and Gynecology. 2013;2013:628-717. doi:10.1155/2013/628717.

19. Bastu E, Akhan SE, Mutlu MF, Nehir A, Yumru H, Hocaoğlu E, et al. Treatment of vaginal agenesis using a modified McIndoe technique: long- term follow -up of 23 patients and a literature review. Can J Plast Surg. 2012;20:241-4.

20. MISHRA, Vineet et al. Youssef's Syndrome - a complication of corrective surgery for mulleriananomaly. International Journal of Reproduction, Contraception, Obstetrics and Gynecology, [S.1.], v. 5, n. 11, p.4091-4, dec. 2016. ISSN 2320-1789. 